\title{
A Case of EBV-Associated Hemophagocytic Lymphohistiocytosis in Adult: Lessons from the Treatment Process
}

\author{
Wanqiu Zhang*, Jiakui Zhang*, Qianshan Tao, Qing Zhang, Yinwei Li, Fan Wu, Zhimin Zhai*\# \\ Department of Hematology, Hematological Research Center, The Second Affiliated Hospital of Anhui Medical University, Hefei, \\ China \\ Email: "zzzm889@163.com
}

How to cite this paper: Zhang, W.Q., Zhang, J.K., Tao, Q.S., Zhang, Q., Li, Y.W., $\mathrm{Wu}, \mathrm{F}$. and Zhai, Z.M. (2020) A Case of EBV-Associated Hemophagocytic Lymphohistiocytosis in Adult: Lessons from the Treatment Process. Open Journal of Blood Diseases, 10, 48-54. https://doi.org/10.4236/ojbd.2020.102006

Received: December 16, 2019

Accepted: June 2, 2020

Published: June 5, 2020

Copyright $\odot 2020$ by author(s) and Scientific Research Publishing Inc. This work is licensed under the Creative Commons Attribution International License (CC BY 4.0).

http://creativecommons.org/licenses/by/4.0/

\section{(c) (i) Open Access}

\begin{abstract}
Hemophagocytic lymphohistiocytosis (HLH), which was first described in 1939 by paediatricians Scott and Robb-Smith, is a life-threatening disease. HLH is characterized as cytokine release syndrome which is caused by excessive but non-malignant activation of macrophages and/or histiocytes in bone marrow and other reticuloendothelial systems. EBV-HLH is the most common type of infection-associated $\mathrm{HLH}$, has a high mortality rate without prompt and effective treatment. A previous study showed that the one-year mortality rate of EBV-HLH patients is $75 \%$. Here we report a case of EBV-associated hemophagocytic syndrome in adult, and the lessons from the treatment process. Through this case, we think that for EBV-related HLH, EBV-DNA should also be monitored in addition to hemophagocytosis-related indicators during treatment. In addition, DEP regimen may not be suitable for patients who have received at least partial response, because impaired immunological functioning may lead to EBV and hemophagocytic re-activity.
\end{abstract}

\section{Keywords}

Hemophagocytic Lymphohistiocytosis, EBV, Infection

\section{Introduction}

Hemophagocytic lymphohistiocytosis (HLH), also known as hemophagocytic syndrome (HPS), which was first described in 1939 by paediatricians Scott and Robb-Smith [1], is a complicated disease with reactive hyperplasia of the mono*These authors contributed equally to this work. 
cyte and/or macrophage system. This disease is characterized by the release of large amounts of cytokines and severe functional destruction of internal organs, which is caused by immune dysfunction resulted from various pathogenic factors. The main clinical symptoms of HLH are constant fever, enlarged liver and spleen, decreased blood cells, coagulation dysfunction caused by hypertriglyceridemia and hypofibrinogenemia, abnormal liver function, elevated serum ferritin, and neurological symptoms. HLH is divided into two categories: primary and secondary. The former mainly occurs in children, most of whom have a family genetic history, and is accompanied by genetic abnormalities, while the latter can occur at all ages, mostly caused by infections, tumors and autoimmune diseases [2]. The secondary hemophagocytic syndrome is mostly a reactive disease caused by the activation mechanism of the immune system for some reason. Its initiation factors are complex and diverse. Those secondary to viral infections are called virus-associated hemophagocytic syndrome (VAHS), the common viruses that cause VAHS are Epstein-Barr virus, cytomegalovirus, varicella-zoster virus, H5N1 influenza virus, etc. [3] [4]. Epstein-Barr virus (EBV) is a double-stranded DNA oncogenic herpesvirus which belongs to $\mathrm{g}$ subfamily of herpesvirus family. Clinical manifestations and prognosis tend to vary depending on the immune status of the hosts. EBV infection is a common infectious disease that often affects multiple organs or systems. It can also cause immune system disordered.

Among them, EBV-HLH is the most common type of infection-associated $\mathrm{HLH}$, has a high mortality rate without prompt and effective treatment [5]. A previous study showed that the one-year mortality rate of EBV-HLH patients is $75 \%$ [6]. The occurrence of HLH caused by EBV is mainly related to the virus invading cytotoxic T lymphocytes (CTL) or/and NK lymphocytes. Therefore, the ability of CTL and NK cells clearing viruses is destroyed, which leads to the activation and proliferation of $\mathrm{B}$ lymphocytes and the massive diffusion of cytokines. And then, macrophages that could engulf blood cells are activated [7] [8], causing a decrease in peripheral blood cells.

However, prior to the HLH-94 regimen, there was no standard or guideline for the treatment of HLH. The combination of etoposide and corticosteroids was used as a chemotherapy regimen to induce clinical symptom relief. HLH-2004 chemo-immunotherapy includes etoposide, dexamethasone, cyclosporine A upfront and, in selected patients, intrathecal therapy with methotrexate and corticosteroids. Subsequent hematopoietic stem cell transplantation (HSCT) is recommended for patients with familial disease or molecular diagnosis, and patients with severe and persistent, or reactivated disease [9]. In addition, supportive treatment should also be emphasized during the treatment of HLH, including empirical application of broad-spectrum antibiotics to prevent infection, prevention of fungal infections, and antiviral treatment for patients with viral infection, intravenous gamma globulin, blood products, etc. However, these treatments are only adjuvant supportive treatments, and cannot fundamentally 
control the development of this disease. Therefore, it is still necessary to explore and study the disease deeply, especially for some patients with scientific significance in cases, also to deeply research the related pathogenic mechanism and more effective treatment methods.

Here we report a case of EBV-associated hemophagocytic lymphohistiocytosis in adult, and the lessons from the treatment process.

\section{Case Presentation}

This study was approved by the Ethics Committee of the Second Affiliated Hospital of Anhui Medical University. All procedures performed in studies involving human participants were in accordance with the ethical standards of the institutional and national research committee. Written informed consent was obtained from the patient for publication of this article and any accompanying images. A copy of the written consent is available for review by the Editor of this journal.

A 43-year-old man was admitted to our hospital on July 9, 2018 because of fever lasts for half a month after catching cold, with reduced leukocytes and platelets for one day. The only past medical history is that he was diagnosed with chronic viral hepatitis B 8 years ago, but only received antiviral therapy for 1 year, no further review was conducted later.

On admission, physical examination shows congestion of throat, bilateral tonsil I degree enlargement and splenomegaly. Results of renal-function tests were normal, as were the routine urine test, stool routine test, antinuclear antibodies, electrolyte, thyroid hormone, immunoglobulin, anticardiolipin antibodies, tumor markers in solid tumors. Tests for tuberculosis antibodies, hepatitis A, hepatitis $\mathrm{C}$, human immunodeficiency virus, syphilis, gonorrhea and chlamydia were all negative. Tests for hepatitis $B$ reveals positive on $\mathrm{HBsAg}, \mathrm{HBeAb}$ and $\mathrm{HBcAb}$, and $\mathrm{HBV}-\mathrm{DNA}<500 \mathrm{IU} / \mathrm{ml}$. IgM and IgG antibodies to tobunia virus, brucella and rickettsia were negative, results of tests for antibodies to cytomegalovirus (CMV) were suggestive of past infection. Torch series antibodies testing toxoplasma gondii, cytomegalovirus, rubella virus and herpes simplex virus I/II all show IgM was negative. Cultures of blood were negative, as were tests for influenza virus, respiratory syncytial virus, adenovirus, and parainfluenza virus types 1, 2, and 3. Urinalysis revealed 1+ albumin and 1+ ketones by dipstick. Abdominal ultrasonography revealed splenomegaly, and urinary system ultrasonography revealed small left kidney stones. Chest computed tomography (CT) suggests a slight inflammation in the left lung. Bone marrow morphology examination shows hemophagocytosis. Bone marrow pathological examination showed myeloproliferative changes. Immunohistochemistry of bone marrow showed EBER (-). Bone marrow chromosome revealed 46, XY. Ten genetic defects related to primary HPS have been identified negative in the patient. sCD25 > $7500 \mathrm{U} /$ liter and NK cell activity shows $1.93 \%$. Other test results are shown in Table 1. According to HLH-2004 diagnostic criteria, the patient 
was diagnosed with HPS. For the significantly increased EBV-DNA of the patient and no evidence of other infections, tumor, autoimmune diseases and genetic defects, the patient was finally diagnosed with EBV-associated HPS. EBV-infected lymphocyte subsets shows negative in CD4+ T cells, CD8+ T cells, CD19+ B cells and CD56+ NK cells.

After definite diagnosis at $4^{\text {th }}$ day in $1^{\text {st }}$ hospitalization, dexamethasone $20 \mathrm{mg}$ per day and IVIG $20 \mathrm{~g}$ per day (for 3 days) was used immediately to control HPS and ganciclovir (250 mg twice a day) for EBV infection (see Figure 1). On the 6th days after diagnosis, fever resolved but EBV-DNA increased to $1.80 \times 10^{4}$ copies $/ \mathrm{ml}$. Acyclovir was administered and the dose of ganciclovir was increased to $425 \mathrm{mg}$ twice a day. On the 12th days after diagnosis, fever reappeared with maximum temperature $39.6^{\circ} \mathrm{C}$. Considering C-reactive protein and procalcitonin was nomal but pancytopenia and serum ferritin worsened, etoposide was administered $200 \mathrm{mg}$ twice a week. On the 15th days after diagnosis, the dosage of dexamethasone was adjusted to $10 \mathrm{mg}$ per day. Subsequently, the patient's body temperature remained normal, and liver function, SF, LDH and FIB gradually improved. On the 26th days after diagnosis, the patient was charged from hospital. Efficacy evaluation shows partial response.

Table 1. Laboratory data during the 1st hospitalization.

\begin{tabular}{|c|c|c|c|c|c|c|c|c|}
\hline Variable & $\begin{array}{l}\text { Reference range, } \\
\text { adults }\end{array}$ & $\begin{array}{l}1^{\text {st }} \text { hospital } \\
\text { day }\end{array}$ & $\begin{array}{l}2^{\text {nd }} \text { hospital } \\
\text { day }\end{array}$ & $\begin{array}{l}4^{\text {th }} \text { hospital } \\
\text { day }\end{array}$ & $\begin{array}{l}6^{\text {th }} \text { hospital } \\
\text { day }\end{array}$ & $\begin{array}{l}12^{\text {th }} \text { hospital } \\
\text { day }\end{array}$ & $\begin{array}{l}19^{\text {th }} \text { hospital } \\
\text { day }\end{array}$ & $\begin{array}{l}26^{\text {th }} \text { hospital } \\
\text { day }\end{array}$ \\
\hline Hemoglobin (g/dl) & $13.0-17.5$ & 12.9 & 12.5 & 12.7 & 11.7 & 11.6 & 10.9 & 10.4 \\
\hline White-cell count (per $\mathrm{mm}^{3}$ ) & $4000-10,000$ & 1880 & 1480 & 2370 & 3180 & 1690 & 1900 & 700 \\
\hline \multicolumn{9}{|l|}{ Differential count (\%) } \\
\hline Neutrophils & $40.0-75.0$ & 67.6 & 56.1 & 81.0 & 34.6 & 69.2 & 63.2 & 21.4 \\
\hline Lymphocytes & $20.0-50.0$ & 21.8 & 25.0 & 15.6 & 43.7 & 18.9 & 34.2 & 71.4 \\
\hline Platelet count (per $\mathrm{mm}^{3}$ ) & $100,000-300,000$ & 62,000 & 52,000 & 29,000 & 46,000 & 60,000 & 76,000 & 75,000 \\
\hline $\begin{array}{l}\text { Alanine aminotransferase } \\
\text { (U/liter) }\end{array}$ & $10-40$ & 148 & & 106 & 225 & 73 & 97 & 43 \\
\hline $\begin{array}{l}\text { Aspartate aminotransferase } \\
\text { (U/liter) }\end{array}$ & $10-40$ & 76 & & 120 & 129 & 58 & 67 & 14 \\
\hline Calcium (mmol/liter) & $2.11-2.52$ & 1.87 & 1.89 & 1.89 & 2.17 & 1.74 & 1.90 & 1.88 \\
\hline Lactic dehydrogenase (U/liter) & $120-250$ & 525 & & 1134 & 425 & 325 & 228 & 195 \\
\hline Fibrinogen (mg/dl) & $1.70-4.00$ & 1.75 & & & 1.12 & 1.25 & 1.50 & \\
\hline Triglycerides (mg/dl) & $0.56-1.70$ & 1.04 & & & 1.28 & 1.0 & 1.05 & 1.98 \\
\hline C-reactive protein (mg/liter) & $<10.0$ & 18.0 & & 44.5 & 7.0 & 2.9 & 1.3 & 0.8 \\
\hline Serum ferritin (ng/ml) & $30-400$ & & & 12,400 & 3128 & 3687 & 1603 & 923 \\
\hline Procalcitonin (ng/ml) & $<0.046$ & 0.112 & & & 0.063 & 0.068 & & \\
\hline IL-6 (pg/ml) & $<7$ & 29 & & & 2 & 16 & & \\
\hline EBV-DNA (copies/ml) & $<1000$ & & 9130 & 18,000 & & $<1000$ & $<1000$ & $<1000$ \\
\hline
\end{tabular}

Dayl was considered as the day admitted to our hospital. 


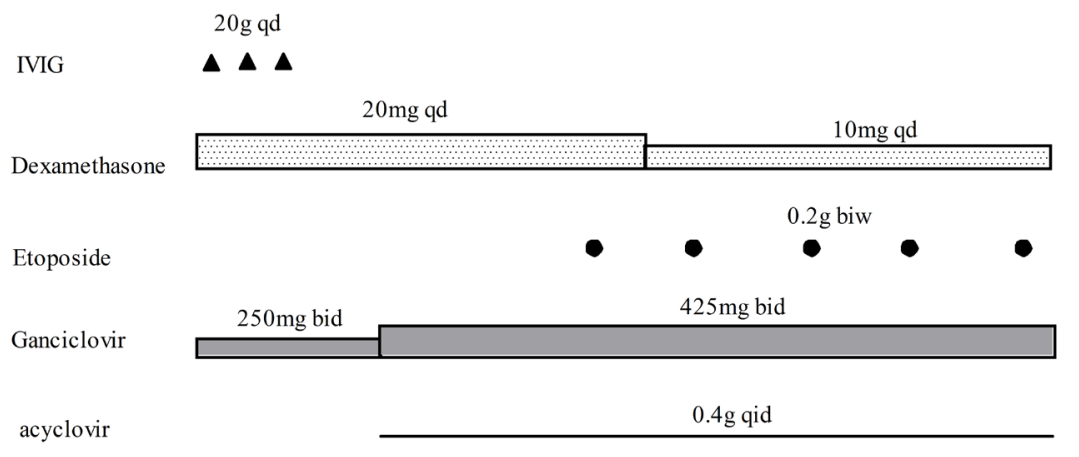

Weeks after diagnosi

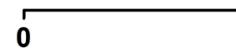

1

2

3

4

Figure 1. Treatment process during 1st hospitalization for the patient. Abbreviations. qd: once a day; biw: twice a week; bid: twice a day; qid: fourth a day.

In addition, considering the patient's past history of hepatitis B, poor immune function and abnormal liver function, entecavir and tenofovir were administered combined with hepatoprotective treatment.

After discharge, the patient stayed at home for four days and took medicine as prescription. Later, the patient visit another hospital and received DEP regimen therapy (liposomal doxorubicin $25 \mathrm{mg} / \mathrm{m}^{2} /$ day, day 1 ; etoposide $100 \mathrm{mg} / \mathrm{m}^{2} /$ day on the first day of every week; and methylprednisolone $15 \mathrm{mg} / \mathrm{kg} /$ day for days 1 to $3,0.75 \mathrm{mg} / \mathrm{kg} / \mathrm{day}$ for days 4 to 7 , and $0.25 \mathrm{mg} / \mathrm{kg} /$ day for days 8 to 10 ). However, high fever occurred again on the 9th day of chemotherapy. Three days later, the patient visited our department again and his condition deteriorated rapidly. EBV-DNA, LDH and serum ferritin increased to 51,700 copies $/ \mathrm{ml}, 4096$ $\mathrm{U} / \mathrm{ml}$ and $295,436 \mathrm{ng} / \mathrm{ml}$, respectively. Platelet and fibrinogen decreased to 8000 per $\mathrm{mm}^{3}$ and $0.6 \mathrm{mg} / \mathrm{dl}$ respectively. Dexamethasone $20 \mathrm{mg}$ per day with gradually reduced per two weeks, ganciclovir ( $425 \mathrm{mg}$ twice a day), cyclosporine (100 mg twice a day) and IVIG 20 g per day (for 3 days) was used immediately. Partial response was achieved 3 weeks later with EBV-DNA undetectable. However, when methylprednisolone reduced to $5 \mathrm{mg}$ per day, the patient's condition deteriorated rapidly. Although we increased the dose of methylprednisolone again, but the patient eventually died two weeks later.

\section{Discussion}

A previous study [10] showed that high viral load of EBV-DNA indicates poor outcomes. The patients with viral load of EBV-DNA more than $1 \times 10^{3}$ copies/ml showed a significantly lower clinical response and shorter overall survival than those with low viral load of EBV-DNA. The first-line treatment for patients with EBV-HLH mainly refers to the HLH-94 regimen, followed by allogeneic hematopoietic stem cell transplantation (allo-HSCT). However, the efficacy of antiviral therapy for EBV-HLH remains unclear, such as ganciclovir and acyclo- 
vir. Here we found that antiviral therapy may be an effective treatment for EBV-related HPS, especially with high viral load of EBV-DNA and negative results of EBV-infected lymphocyte subsets.

To this patient, EBV-DNA is closely related to the severity of the disease. This is also confirmed by other studies [11]. So, for EBV-related HLH, EBV-DNA should also be monitored in addition to hemophagocytosis-related indicators during treatment.

In addition, DEP regimen has been proven an effective treatment for relapsed/refractory EB virus-related HPS [12], but it may not be suitable for patients who have received at least partial response. We think that in this case, immunological functioning of the patients will be impaired, which will lead to EBV and hemophagocytic re-activity.

\section{Conclusion}

EBV-HLH usually has high fatality rate without prompt and effective treatment. EBV infection can cause immune system disordered. Chemotherapy regimen that is effective for primary HLH, such as DEP, is less effective for EBV-HLH. Considering this case, patient's rapid deterioration may be related to his own immune system being destroyed and weakened resistance to chemotherapy. Therefore, the therapy of EBV-HLH is more individualized, and the program should be adjusted at any time according to the fluctuation of vital signs and relevant indicators of patient. Controlling the disease itself and strengthening supportive treatment should be given the same importance. Both are equally important.

\section{Acknowledgements}

This work is funded by the National Natural Science Foundation of China (grant no. 81670179) and the Natural Science Research Project of Anhui Medical University (grant no. KJ2019A0274). The authors thank the patient and his family and all the investigators, including the physicians and laboratory technicians in this study.

\section{Conflicts of Interest}

The authors declare no conflicts of interest regarding the publication of this paper.

\section{References}

[1] Scott, R.B. and Robb-Smith, A.H. (1939) Histiocytic Medullary Reticulocytosis. Lancet, 2, 194-198.

[2] Niu, Y., He, A. and Zhang, W. (2010) Research Advance on Hemophagocytic Lymphohistiocytosis-Review Progress of Research on Hemophilic Lymphoid Histiocytosis. Chinese Journal of Experimental Hematology, 18, 262-267.

[3] To, K.F., Chan, P.K., Chan, K.F., et al. (2001) Pathology of Fatal Human Infection 
Associated with a Vian Influenza AH5N1 Virus. Journal of Medical Virology, 6, 242-246.

[4] Imashuku, S. (2002) Clinical Features and Treatmen Tstrategies of Epstein-Barrvirus-Associated Hemophagocytic Lymphohistiocytosis. Critical Reviews in Oncology/Hematology, 44, 259-272. https://doi.org/10.1016/s1040-8428(02)00117-8

[5] Maakaroun, N.R., Moanna, A., Jacob, J.T., et al. (2010) Viral Infections Associated with Haemophagocytic Syndrome. Reviews in Medical Virology, 20, 93-105. https://doi.org/10.1002/rmv.638

[6] Zeng, X., Wei, N., Wang, Y., et al. (2015) Treatment Outcomes and Prognostic Analysis of 61 Epstein-Barr Virus-Associated Hemophagocytic Lymphohistiocytosis. Zhonghua Xue Ye Xue Za Zhi, 36, 507-310.

[7] Kimura, H., Ito, Y., Kawabe, S., et al. (2012) EBV-Associated T/NK Cell Lymphoproliferative Diseases in Nonimmunocompromised Hosts: Prospective Analysis of 108 Cases. Blood, 119, 673-686. https://doi.org/10.1182/blood-2011-10-381921

[8] Imashuku, S. (2011) Treatment of Epstein-Barr Virus-Related Hemophagocytic Lymphohistiocytosis (EBV-HLH): Update 2010. Journal of Pediatric Hematology/Oncology, 33, 35-39. https://doi.org/10.1097/mph.0b013e3181f84a52

[9] Henter, J.I., Horne, A., Aricó, M., et al. (2007) HLH-2004: Diagnostic and Therapeutic Guidelines for Hemophagocytic Lymphohistiocytosis. Pediatric Blood \& Cancer, 48, 124-131. https://doi.org/10.1002/pbc.21039

[10] Ahn, J.S., Rew, S.Y., Shin, M.G., et al. (2010) Clinical Significance of Clonality and Epstein-Barr Virus Infection in Adult Patients with Hemophagocytic Lymphohistiocytosis. American Journal of Hematology, 85, 719-722. https://doi.org/10.1002/ajh.21795

[11] Ishii, E., Ohga, S., Imashuku, S., et al. (2007) Nationwide Survey of Hemophagocytic Lymphohistiocytosis in Japan. International Journal of Hematology, 86, 58-65. https://doi.org/10.1532/ijh97.07012

[12] Wang, Y., Huang, W., Hu, L., et al. (2015) Multicenter Study of Combination DEP Regimen as a Salvage Therapy for Adult Refractory Hemophagocytic Lymphohistiocytosis. Blood, 126, 2186-2192. https://doi.org/10.1182/blood-2015-05-644914 